\title{
Geociênciajass
}

\section{Mineralogia e proveniência das areias negras de Iriri - ES}

\author{
Mineralogy and provenance \\ of black sands from Iriri - ES
}

\begin{abstract}
Alexandre de Oliveira Chaves
Instituto de Geociências, Univ. Fed. de Minas Gerais - IGC/UFMG, Belo Horizonte - MG alochaves@yahoo.com.br
\end{abstract}

\section{Débora Vasconcelos de Oliveira \\ Aluna de Graduação, Instituto de Geociências, Univ. Fed. de Minas Gerais - IGC/UFMG, \\ Belo Horizonte - MG \\ debh03@hotmail.com}

\section{Fernando Estevão Rodrigues Crincoli Pacheco}

Aluno de Graduação, Instituto de Geociências, Univ. Fed. de Minas Gerais - IGC/UFMG,

Belo Horizonte - MG

ferodrigues@live.it

\section{Mariana Franco Barroso}

Aluna de Graduação, Instituto de Geociências, Univ. Fed. de Minas Gerais - IGC/UFMG,

Belo Horizonte - MG

miana_fb@hotmail.com

\section{Marina Garcia de Magalhães}

Aluna de Graduação, Instituto de Geociências, Univ. Fed. de Minas Gerais - IGC/UFMG,

Belo Horizonte - MG

marinamg1@hotmail.com

\section{Adriana Mônica Dalla \\ Vecchia Chaves}

Doutoranda, Centro de Desenvolvimento da Tecnologia Nuclear - CDTN/CNEN, Belo Horizonte - MG

amdvecchia@yahoo.com.br

\section{Resumo}

As areias negras das praias de Iriri (ES) apresentam uma ampla variedade no seu conteúdo mineralógico. A partir de propriedades ópticas e morfológicas e das composições químicas de grãos individuais, foi verificado que os principais minerais são quartzo e ilmenita, constituindo, respectivamente, $45 \%$ e $35 \%$ do volume do material investigado. Na porção restante, foram identificados os minerais pesados magnetita, monazita, zircão, cianita, sillimanita, granadas almandina e grossulária, espinélio, actinolita, clorita, rutilo e augita, além de aragonita. Levando-se em conta a geologia regional, tanto da área continental, quanto da bacia sedimentar, que envolve a região de Iriri, a análise de proveniência sugere que: a) o quartzo seja oriundo dos paragnaisses regionais, dos granitóides pré a sin-colisionais e dos granulitos costeiros; b) a associação dos minerais ilmenita, magnetita, augita e chamosita seja proveniente de basaltos toleíticos amigdalóides mesozóicos da bacia; c) a grossulária, o espinélio e a actinolita provenham de ortoanfibolitos e rochas cálcio-silicáticas; d) a almandina tenha origem relacionada não só aos paragnaisses como também aos granitóides peraluminosos sincolisionais regionais e granulitos costeiros, sendo que estes últimos também podem ter sido a rocha-fonte do rutilo; e) a cianita seja originária do terreno Cabo Frio; f) a sillimanita provenha dos sillimanita-granada-biotita gnaisses paraderivados situados próximo à costa do Espírito Santo; g) um primeiro subtipo de zircões juntamente com as monazitas sejam derivados das suítes pós-colisonais G4 e G5 e um segundo grupo de zircões representem cristais do embasamento paleoproterozóico distante da área de deposição; h) a aragonita possua uma origem biogênica, sendo derivada de fragmentos de conchas de moluscos ou corais marinhos.

Palavras-chave: Iriri, areias negras, minerais pesados, mineralogia, proveniência.

\begin{abstract}
Black sands from the Iriri beach (ES) present a wide variety in their mineral content. From the optical and morphological properties and the chemical compositions of individual grains, it was found that crystals of quartz $(45 \%$ vol.) and ilmenite $(35 \%$ vol.) represent the main mineral phases of the material. In the remaining portion, the heavy minerals of magnetite, monazite, zircon, kyanite, sillimanite, almandine and grossular garnets, spinel, actinolite, chlorite, rutile, augite and aragonite have been found. Taking into account the regional geology of the continental area and sedimentary basin surrounding Iriri, the provenance analysis suggests that: a) the quartz originates from the regional paragneisses, the pre to syn-collisional granitoids and the coastal granulites, b) the association of ilmenite, magnetite, angite, and chamosite arises from Mesozoic amygdaloid tholeiitic basalts of the basin, c) grossular, spinel, and actinolite come from orthoamphibolites and calc-silicate rocks, d) almandine
\end{abstract}


arises not only from paragneisses but also as syn-collisional peraluminous granitoids and coastal granulites, and the latter rocks also have been the source of rutile; e) kyanite is from the Cabo Frio terrain; f) sillimanite comes from the sillimanite-garnetbiotite paragneisses located near the Espirito Santo coast, g) a zircon subtype, along with monazite, arises from post-collisional G4 and G5 suites and another group of zircon represents crystals of the Paleoproterozoic basement away from the area of deposition; h) aragonite has a biogenic origin, from fragments of mollusk shells or coral reefs.

Keywords: Iriri, black sands, heavy minerals, mineralogy, provenance.

\section{Introdução}

Acumulações sedimentares de minerais detríticos de valor econômico concentrados mecanicamente, originados a partir da decomposição e erosão de rochas-fonte ígneas, metamórficas e sedimentares, são denominadas placers. Esses minerais detríticos são, geralmente, conhecidos como "minerais pesados", em função de seu alto peso específico (entre 21,0 e $2,9 \mathrm{~g} / \mathrm{cm}^{3}$ ) superior ao do quartzo $\left(2,65 \mathrm{~g} / \mathrm{cm}^{3}\right)$. Os placers são compostos por minerais pesados "pesados" (peso específico entre 21,0 e $\left.6,8 \mathrm{~g} / \mathrm{cm}^{3}\right)$, por minerais pesados "leves" (peso específico entre 5,3 e $\left.4,2 \mathrm{~g} / \mathrm{cm}^{3}\right)$, ambos fontes de bens metálicos, e por gemas (peso específico entre 4,1 e $\left.2,9 \mathrm{~g} / \mathrm{cm}^{3}\right)$. Os pesados "pesados" são transportados apenas por curtas distâncias e englobam, principalmente, o ouro, a platina e a cassiterita. Os pesados "leves", principais objetos de estudo desse artigo, chegam mais comumente às zonas costeiras, concentrando-se em ambientes de deposição de alta energia. Eles compreendem, principalmente, a ilmenita, o rutilo, o zircão, a monazita e a magnetita. Nas regiões costeiras e plataforma continental, os depósitos de minerais pesados têm sua gênese associada aos fenômenos de erosão, transporte e deposição de sedimentos pela ação das ondas e correntes costeiras, em íntima associação com as modificações decorrentes das variações eustáticas do nível do mar (Silva, 2000).

As areias do litoral sul do Espírito Santo, eventualmente, mostram porções escuras, popularmente conhecidas como monazíticas, formando depósitos de placers. Uma significativa parcela desse material é constituída por minerais pesados opacos, os quais conferem à areia sua tonalidade escura.

A análise do conteúdo mineralógico depositado em bacias é uma ferramenta crescentemente utilizada para a identificação litológica das áreas-fonte,

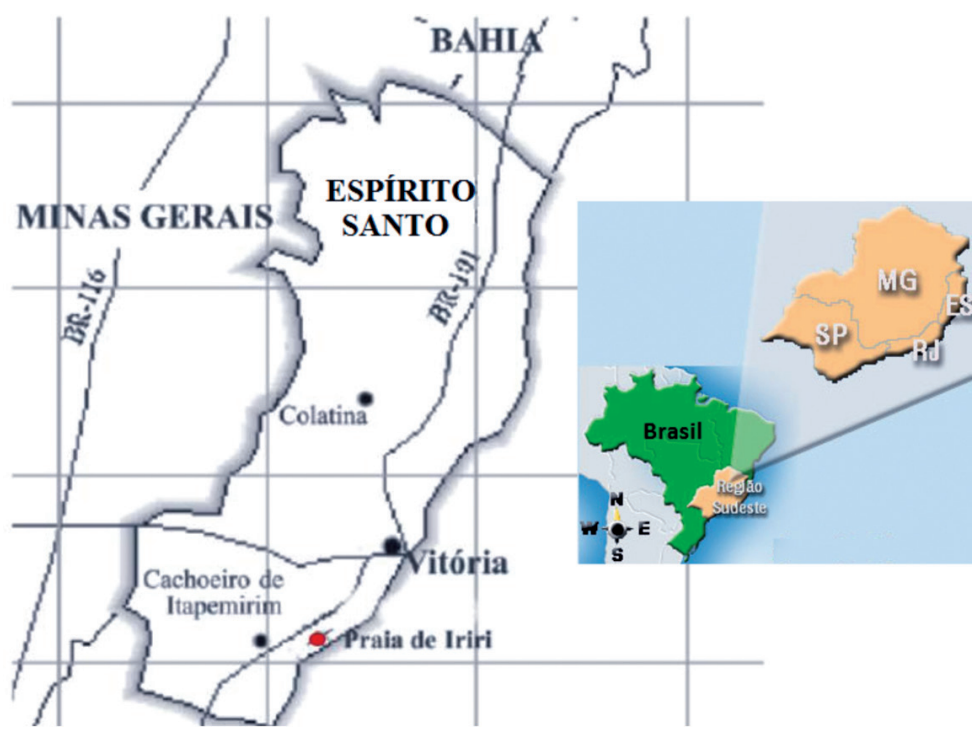

inferência de sua localização geográfica e determinação das principais rotas de distribuição das areias. A diversidade de minerais pesados encontrada em areias e a ocorrência de associações diagnósticas de rochas-fonte particulares tornam a análise de minerais pesados a técnica mais sensível e robusta aplicada na análise de proveniência (Remus et al., 2008).

$\mathrm{O}$ presente trabalho tem como objetivo a caracterização da mineralogia das areias negras coletadas na Praia de Iriri - ES (Figura 1), através da investigação de suas propriedades óptico/morfológicas e químicas, para fins de estudos de sua proveniência e definição de áreas-fonte. A Praia de Iriri foi escolhida por localizar-se, estrategicamente, entre rochas sedimentares costeiras do Neógeno e no encontro das rochas cristalinas continentais e da bacia de Campos (Figura 2), todas potenciais áreas-fonte das referidas areias negras.

Figura 1

Localização da área de amostragem na praia de Iriri, litoral sul do Estado do Espírito Santo (MG - Minas Gerais, SP - São Paulo, RJ - Rio de Janeiro, ES - Espírito Santo; modificado de Coelho et al., 2005).

\section{Arcabouço geológico}

A Praia de Iriri se encontra na porção norte da bacia de Campos (Figura 2), bacia que se estende do sul do Espírito Santo e prolonga-se pelo Estado do
Rio de Janeiro. É limitada a norte e a sul pelos altos estruturais de Vitória e Cabo Frio, respectivamente, e tem origem relacionada à abertura do oceano Atlântico
Sul (Fontanelli et al., 2009). Seu preenchimento sedimentar pode ser caracterizado em cinco mega-seqüências: rifte continental (Neocomiano - início do 
Figura 2

Geologia do Estado do Espírito Santo e de parte dos Estados do Rio de Janeiro e Minas Gerais. 1 - Cinturões do Arqueano e Paleoproterozóico; 2 - Terreno

Ocidental - Unidades Paleoproterozóicas;

3 - Complexo Região dos Lagos.

Unidades Neoproterozóicas; 4 - Metaultramáficas; 5 - Grupo Rio Doce;

6 - Complexo Kinzigítico; 7 - Unidades Búzios e Palmital; 8 - Granitos précolisionais (Suíte G1); 9 - Charnockitóides indiferenciados; 10 - Granitóides sin-colisionais (suítes G2 e G3); 11 Granitóides pós-colisionais (suítes G4 e G5); 12 - Intrusões alcalinas cenozóicas; 13 - Sedimentares do Neógeneo.

CF: Limite tectônico do terreno Cabo

Frio; G: Falha Guaçuí; V: Zona de falha Vitória-Colatina (modificado de Fontanelli et al., 2009).

Aptiano), salientando-se a ocorrência de basaltos toleíticos amigdaloidais da Formação Cabiúnas na base da coluna sedimentar, com datação radiométrica entre 134 e 122 Ma (Mizusaki et al. 1988), transicional evaporítica (médio Aptiano - início do Albiano), marinha rasa (início - final do Albiano), marinha transgressiva (final do Albiano - início do Terciário) e marinha regressiva (início do Terciário - recente). Na bacia de Campos, existem dois estilos estruturais distintos: o primeiro consiste num sistema de horsts e grabens de direção SW - NE, relacionado à fase rifte. $\mathrm{O}$ segundo, gerado no início do Albiano, consiste no crescimento de falhas associado a um regime extensivo nos primeiros $100-200 \mathrm{~km}$ ao longo da costa. Paralela à margem da bacia, existe uma importante estrutura nomeada Falha de Campos ou Linha de Charneira do Cretáceo. Nessa falha, em sua porção oeste, os sedimentos terciários são encontrados diretamente sobre o embasamento pré-cambriano enquanto sedimentos cretáceos aparecem na sua porção leste. (Fontanelli et al., 2009).

O embasamento da bacia de Campos é composto por gnaisses paraderivados e granito-gnaisses de alto grau pertencentes à Província Tectônica Mantiqueira. Nessa região, a província apresenta um sistema orogênico neoprotero-

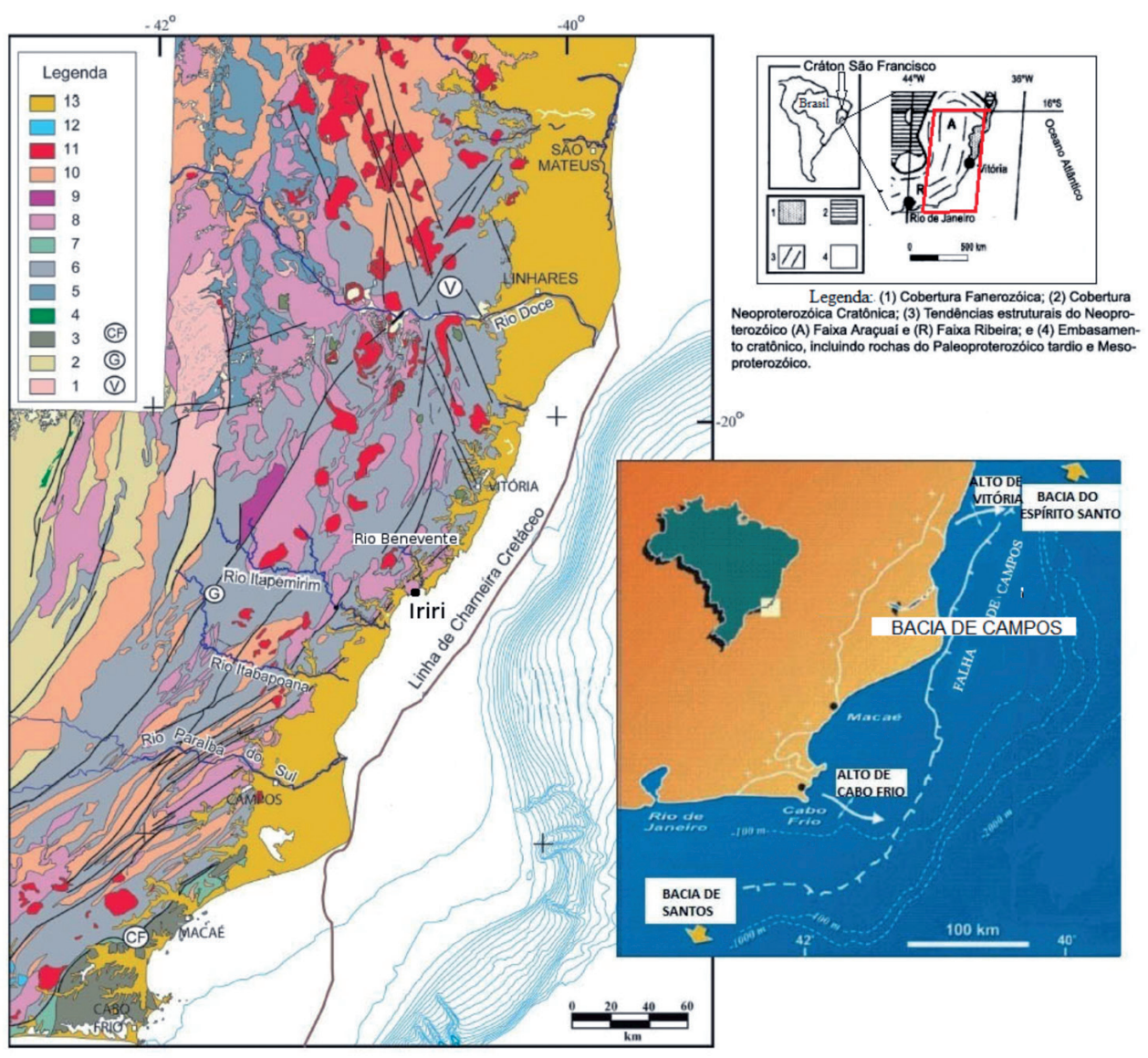

zóico desenvolvido na borda sudeste do Cráton São Francisco durante a Orogênese Brasiliana - Pan-Africana (650-490 Ma) e inclui parte dos orógenos Ribeira e Araçuaí. Esses orógenos são estruturados em domínios externo e interno, sendo o primeiro localizado mais a oeste e composto por embasamento antigo (mais velho que $1,8 \mathrm{Ga}$ ). Nessa porção, o metamorfismo varia de fácies xisto-verde (próximo à borda do Cráton São Francisco) a fácies anfibolito alto ou granulito de média pressão (próximo ao limite do domínio interno).

O domínio interno, também nomeado de Terreno Oriental ou Cinturão Ribeira, se localiza a leste e encontra-se adjacente à bacia. É constituído por uma grande unidade nomeada "Complexo Kinzigítico”, composto por paragnaisses aluminosos e variações do mesmo, incluindo cordierita-granada-biotita gnaisse, granada-biotita gnaisse ou biotita gnaisse com lentes de mármore, grafita, quartzito, rochas cálcio-silicáticas paraderivadas e ortoanfibolitos. Próximo à costa, os paragnaisses tornam-se mais ricos em alumínio com grafita-sillimanita-cordierita-granada-biotita gnaisse e, apresenta, em menor quantidade, granulitos charno-enderbíticos. As unidades foram submetidas a processos de metamorfismo que variam de fácies anfibolito alto a granulito, sendo comum a fusão parcial sob diferentes graus de anatexia. Ainda no domínio interno, aloja-se o Grupo Rio Doce, composto por metagrauvacas, estaurolita-granada-mica xisto, quartzitos e gnaisses bandados com metamorfismo de fácies xisto-verde a anfibolito. O domínio ainda apresenta arcos magmáticos pré e sin-colisionais e vários plútons tardi a pós-colisionais. $\mathrm{O}$ arco continental pré-colisional é formado por gnaisses granodioríticos tipo-I e tonalíticos e é, genericamente, denominado de suíte G1. O arco sin-colisional foi desenvolvido concomitantemente ao metamorfismo e às deformação regionais. Genericamente representado pela suíte $\mathrm{G} 2$, é formado por granada-biotita gnaisses foliados, que contêm grande quantidade de minerais acessórios ricos em alumínio e restos de paragnaisses bandados e migmatitos. A fase G2 foi fundida dando origem aos leucogranitos tipo-S tardi-colisionais da suíte G3. A suíte G3 tipo-I é formada por plutons graníticos a granodioríticos, que intrudiram zonas de cisalhamento. As suítes G4 e G5 tipo-I foram formadas pelo magmatismo pós-colisional, sendo a suíte G4 constituída por plútons graníticos com pegmatitos ricos em turmalina e a G5 por plútons sem foliação, podendo ser zonados com gabro no núcleo e 
granito nas bordas. A suíte G5 é intrudida ao longo de zonas de cisalhamento e tem ocorrência mais ampla que a suíte G4. Em termos regionais, o pico do metamorfismo ocorreu durante a fase sincolisional, entre 590 e 560/550 Ma, em associado à deformação principal, que gerou a foliação regional das diversas litologias. O último terreno acrescido foi o Cabo Frio, cujo limite a oeste com o terreno oriental é definido por uma falha de empurrão (CF - Figura 2). Esse episódio durou de 530 a 490 Ma, e é contemporâneo às suítes G4 e G5. Por fim, rochas ígneas alcalinas cretácico-terciárias posicionaram-se na região do Estado do Rio de Janeiro e a cobertura sedimentar terciária estendeu-se ao longo da região costeira dos Estados do Rio de Janeiro e Espírito Santo (Fontanelli et al., 2009).
A praia de Iriri encontra-se próxima à foz do rio Benevente, que, juntamente com seus afluentes, representam o sistema de drenagem local que atravessa não só o "Complexo Kinzigítico" como também ortognaisses graníticos e granulitos. Essas rochas representam as principais áreas-fonte continentais das proximidades da praia de Iriri.

\section{Metodologia}

A amostra de areia negra coletada, cuja fração granulométrica está entre 0,1 e $0,3 \mathrm{~mm}$, foi submetida a processos de separação baseados nas diferenças das propriedades físicas de seus constituintes. Inicialmente foi submetida à separação usando-se o líquido denso bromofórmio $\left(\rho=2,89 \mathrm{~g} / \mathrm{cm}^{3}\right)$ em funil de decantação, a fim de se separarem os minerais menos densos, principalmente o quartzo e eventuais feldspatos $\left(\rho=2,65 \mathrm{~g} / \mathrm{cm}^{3}\right)$, daqueles ditos pesados. Em seguida, foi feita a separação magnética dos minerais mais densos que o bromofórmio através do separador magnético Frantz, o qual isolou duas diferentes fases minerais opacas do restante dos não-opacos da amostra. Estes últimos minerais pesados não-opacos foram sub-

\section{Resultados}

Nas areias negras de Iriri, foram encontrados $45 \%$ em volume de quartzo e $35 \%$ em volume de ilmenita. Os $20 \%$ restantes compõem a porção dos demais minerais pesados também encontrados, sendo a quarta parte deles composta por zircões. Além disso, não aparecem feldspatos nem fragmentos líticos. As fórmulas químicas dos minerais identificados e descritos a seguir foram obtidas a partir de Klein e Dutrow (2008).

Quartzo $\left(\mathrm{SiO}_{2,}, \mathrm{\rho}=2,65 \mathrm{~g} / \mathrm{cm}^{3}\right)$ : granulometria areia fina, grãos de baixa esfericidade, subarredondados, incolores e extinção ondulante (Figura 3). Foram totalmente separados dos minerais pesados através do bromofórmio. Como esperado, o espectro EDS indicou somente Si e O.

Ilmenita $\left(\mathrm{FeTiO}_{3,} \rho=4,72 \mathrm{~g} / \mathrm{cm}^{3}\right)$ : fração opaca de granulometria areia fina a muito fina, grãos subédricos, de baixa esfericidade, subangulosos (Figura 3). Apesar do fraco magnetismo, foi possível sua remoção da amostra através do separador magnético Frantz. Os dados qualitativos do espectro EDS indicam metidos à separação através de suas propriedades ópticas. Para isso, foi utilizado o microscópio petrográfico Zeiss (modelo Axioskop 40), no qual foram isolados, por meio de catação utilizando-se uma fina agulha de cobre, os minerais através de suas características peculiares sob luz transmitida natural, polarizada e polarizada/analisada como isotropia/anisotropia, cor, pleocroísmo, morfologia, cor de interferência, entre outras. A identificação dos minerais separados nessa etapa contou com o apoio das imagens e informações técnicas contidas no livro Heavy Minerals in Colour (Mange \& Maurer, 1992). Mencionados nos resultados a seguir, os critérios de forma utilizados foram as razões entre os eixos longo, intermediário

Fe, Ti e O, elementos constituintes desse mineral.

Magnetita $\quad\left(\mathrm{Fe}_{3} \mathrm{O}_{4}, \quad \rho=5,10\right.$ $5,20 \mathrm{gcm}^{3}$ ): granulometria areia fina a muito fina, grãos subédricos, de baixa esfericidade, subangulosos e opacos ao microscópio óptico de luz transmitida. Os grãos foram prontamente retirados da amostra através do separador magnético Frantz devido ao forte magnetismo. Diferentemente dos grãos de ilmenita, o espectro EDS não mostra Ti (Figura 3).

Monazita (Ce,La,Nd,Th) $\mathrm{PO}_{4}$, $\rho=5,00-5,30 \mathrm{~g} / \mathrm{cm}^{3)}$ : granulometria areia fina, grãos anédricos verde-pálido, de baixa esfericidade, arredondados a subarredondados, de alta birrefringência e relevo muito alto. Os dados do espectro EDS indicam Ce, La, Nd, Th, P e O (Figura 3).

Aragonita $\left(\mathrm{CaCO}_{3}, \rho=2,93 \mathrm{~g} / \mathrm{cm}^{3}\right)$ : granulometria areia fina, subédricos, baixa esfericidade, arredondados. $\mathrm{O}$ espectro EDS acusou $\mathrm{Ca}, \mathrm{C}$ e $\mathrm{O}$, os quais confirmam ser carbonato de cálcio ( $\mathrm{Fi}$ gura 4). Por ter sido separada junto com outros minerais pesados devido ao fato e curto dos cristais. Para esfericidade e arredondamento, foram utilizados os conceitos de Shepard e, para tamanho, foi utilizada a escala granulométrica de sedimentos terrígenos de Wentworth (Wentworth, 1922; Suguio, 2003).

Posteriormente, todas as fases minerais individualizadas foram submetidas às análises químicas qualitativas por EDS (método que dispensa o uso de padrões analíticos), usando-se a microssonda eletrônica Jeol JXA-8900 RL WD/ ED do Laboratório de Microanálises do Departamento de Física da Universidade Federal de Minas Gerais. Em suma, a caracterização mineralógica foi feita tomando-se como base propriedades ópticas, morfológicas e químicas dos grãos.

de possuir densidade maior que do bromofórmio, não se trata de calcita, mas, sim, desse polimorfo do $\mathrm{CaCO}_{3}$.

Zircão $\left(\mathrm{ZrSiO}_{4}, \rho=4,60-4,70 \mathrm{~g} /\right.$ $\mathrm{cm}^{3}$ ): dois subtipos foram identificados, ambos de granulometria areia fina: um deles mostra-se incolor, euédrico, bastonado com terminações pontiagudas e comumente com inclusões fundidas bem preservadas e o outro marrom, subédrico, com bordas arredondadas e fraturado. Os elementos presentes em sua fórmula são confirmados pelo espectro EDS (Figura 4).

Cianita e Sillimanita (polimorfos do $\mathrm{Al}_{2} \mathrm{SiO}_{5,} \rho(\mathrm{cian})=3,.61 \mathrm{~g} / \mathrm{cm}^{3}$, $\rho($ sillim. $\left.)=3,25 \mathrm{~g} / \mathrm{cm}^{3}\right)$ : granulometria areia fina a média, euédricas a subédricas, muitas vezes bastonadas, baixa esfericidade e angulares. Quando bastonada, a cianita assemelha-se ao zircão incolor, entretanto suas terminações não são pontiagudas (Figura 4). Foram identificados cristais, tanto com extinção oblíqua de, aproximadamente, $30^{\circ}$ na direção de maior elongamento do cristal (cianita - triclínica) quanto com extin- 
ção paralela (sillimanita - ortorrômbica, com elongação positiva, o que descarta a possibilidade de ser andaluzita). O espectro EDS de ambos os minerais mostra Al, Si e O (Figura 4).

Almandina $\left(\mathrm{Fe}_{3} \mathrm{Al}_{2} \mathrm{Si}_{3} \mathrm{O}_{12}, \rho=4,10\right.$ a $4,30 \mathrm{~g} / \mathrm{cm}^{3}$ ): opticamente isotrópica, granulometria areia fina a média, grãos anédricos, de baixa esfericidade, subangulosos, avermelhados e relevo alto. Além dos elementos que constituem sua fórmula química, o espectro EDS acusa algum $\mathrm{Ca}$ e $\mathrm{Mg}$ (Figura 5).

Grossulária $\left(\mathrm{Ca}_{3} \mathrm{Al}_{2} \mathrm{Si}_{3} \mathrm{O}_{12}, \rho=3,40\right.$ a $3,70 \mathrm{~g} / \mathrm{cm}^{3}$ ): opticamente isotrópica, granulometria areia fina, verde-pálida. Grãos subédricos a anédricos, de alta esfericidade, arredondados e relevo alto. Além do alto teor em $\mathrm{Ca}$ e $\mathrm{Al}$, a análise de microssonda por EDS mostra um pico de Fe (Figura 5).
Figura 3

Fotomicrografia e espectro EDS de ilmenita (1), magnetita (2), monazita (3,4 e 5), além do quartzo.
Espinélio $\left(\mathrm{MgAl}_{2} \mathrm{O}_{4}, \rho=3,60 \mathrm{~g} /\right.$ $\mathrm{cm}^{3}$ ): granulometria areia muito fina, grãos anédricos, de alta esfericidade, arredondados, relevo alto. Assim como as granadas, é opticamente isotrópico, entretanto a análise de microssonda por EDS não forneceu Si (não-silicato), mas apenas picos de $\mathrm{Mg}$, $\mathrm{Al}$ e $\mathrm{O}$ (Figura 5), o que o caracteriza de fato como um óxido.

Actinolita $\quad\left((\mathrm{Ca}, \mathrm{Na})_{2}(\mathrm{Mg}, \mathrm{Fe})_{5}(\mathrm{Si}, \mathrm{A}\right.$ 1) ${ }_{8} \mathrm{O}_{22}(\mathrm{OH})_{2,} \rho=3,00$ a $\left.3,10 \mathrm{~g} / \mathrm{cm}^{3}\right)$ : granulometria areia fina, grãos anédricos verdes, de baixa esfericidade, subarredondados, relevo alto. Espectro EDS mostra seus principais cátions, exceto o $\mathrm{Na}$ (Figura 5).

Chamosita - grupo da clorita $\left(\left(\mathrm{Fe}^{2+}, \mathrm{Mg}, \mathrm{Fe}^{3+}\right)_{5} \mathrm{Al}\left(\mathrm{Si}_{3} \mathrm{Al}\right) \mathrm{O}_{10}(\mathrm{OH}, \mathrm{Cl})_{8}\right.$, $\rho=3,00$ a $3,40 \mathrm{~g} / \mathrm{cm}^{3}$ ): granulometria areia muito fina, grãos anédricos, de baixa esfericidade, subangulosos, relevo médio e têm cor verde semelhante à actinolita. Além dos seus principais cátions, o espectro EDS mostra pico de $\mathrm{Cl}$. (Figura 5).

Rutilo $\left(\mathrm{TiO}_{2,} \rho=4,25 \mathrm{~g} / \mathrm{cm}^{3}\right)$ : granulometria areia fina, grãos euédricos, geralmente bastonados, de baixa esfericidade, angulosos e relevo alto. Espectro EDS mostra picos de Ti e O (Figura 5) e sua típica coloração marrom-avermelhada descarta a possibilidade de ser anatásio.

Augita $\quad((\mathrm{Ca}, \mathrm{Na})(\mathrm{Mg}, \mathrm{Fe}, \mathrm{Al}, \mathrm{Ti})$ $(\mathrm{Si}, \mathrm{Al})_{2} \mathrm{O}_{6}, \mathrm{\rho}=3,20$ a $\left.3,60 \mathrm{~g} / \mathrm{cm}^{3}\right)$ : granulometria areia fina, grãos anédricos, de alta esfericidade, arredondados, verdeescuros e relevo alto. Como era de se esperar pela sua fórmula, além de $\mathrm{Ca}, \mathrm{Mg}$, $\mathrm{Fe}$ e $\mathrm{Al}$, a análise de microssonda por EDS gerou picos de $\mathrm{Na}$ e $\mathrm{Ti}$ (Figura 5).

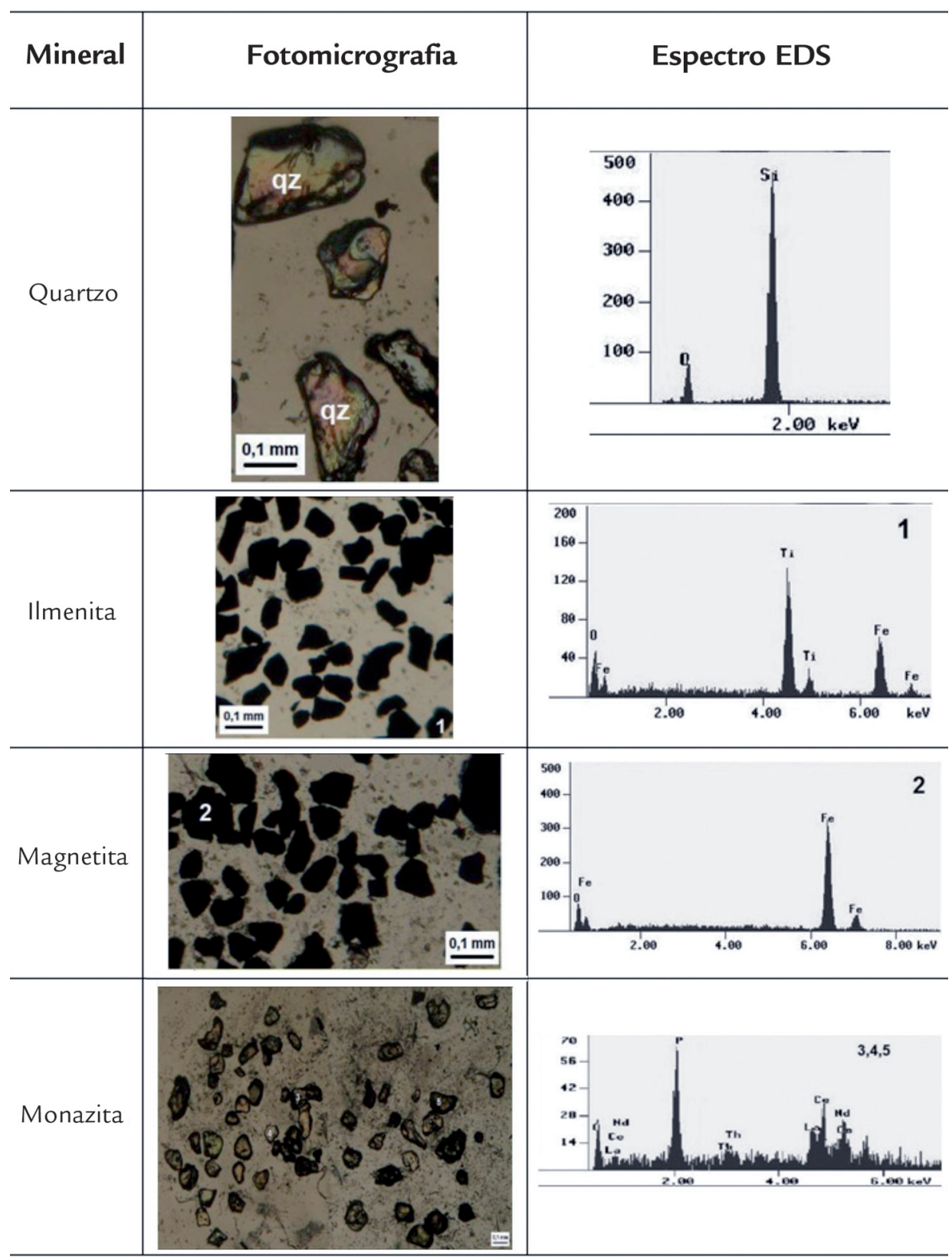




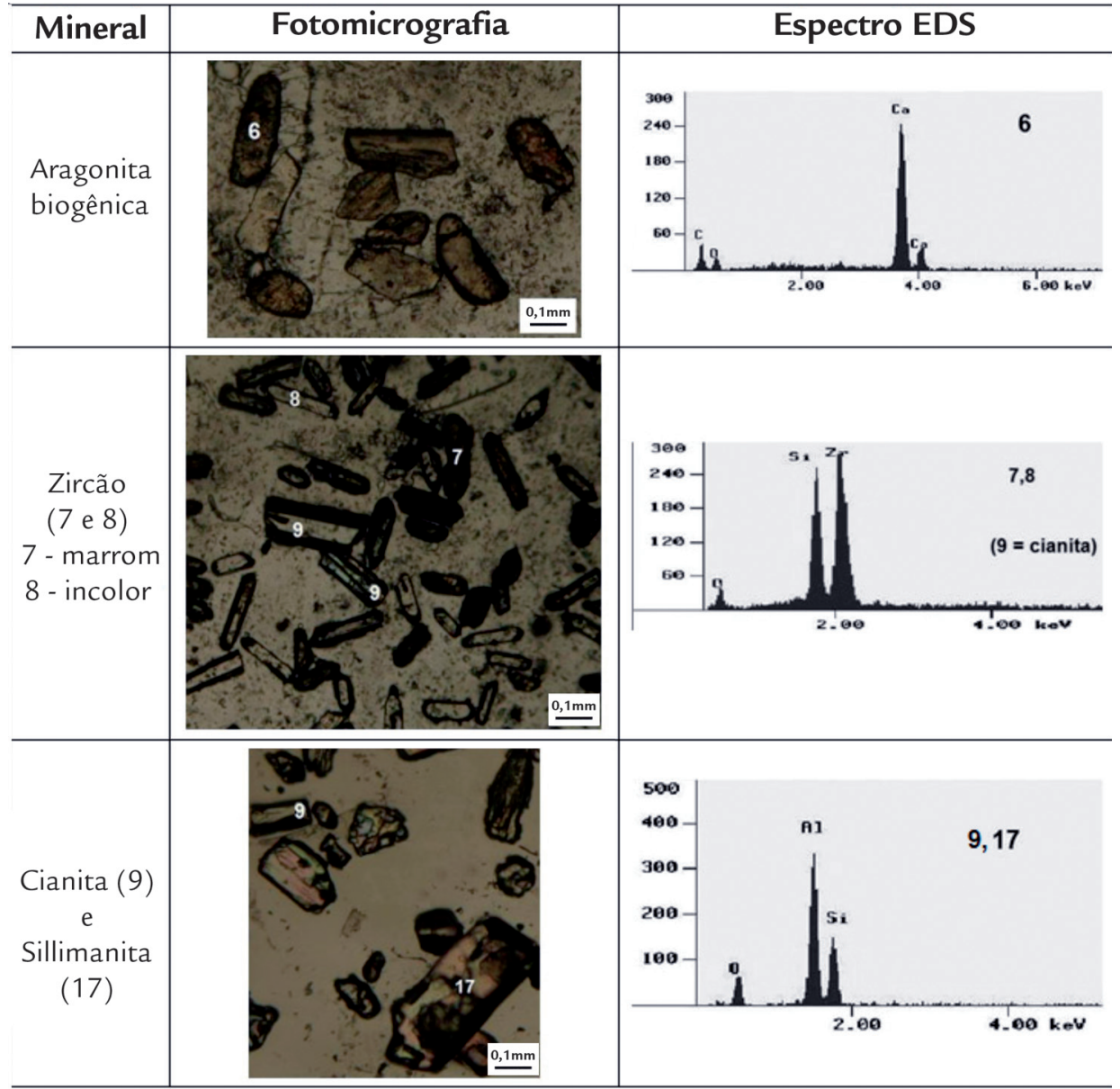

\section{Discussões e conclusões}

A mineralogia das areias depositadas no litoral sul-capixaba tem muito a dizer sobre as características litológicas das áreas-fonte, levando a inferir sua localização geográfica, a determinar as principais rotas de distribuição das areias. A diversidade de minerais pesados encontrados nessas areias e a ocorrência de associações diagnósticas de rochasfonte particulares, discutidas a seguir, auxiliam na análise de proveniência.

O quartzo, polimorfo mais comum dos minerais de fórmula $\mathrm{SiO}_{2}$, representa a principal fase mineral das areias negras de Iriri e representa um importante constituinte de rochas-fonte ígneas, metamórficas e sedimentares. Entretanto, dado o caráter ondulante de sua extinção óptica, esses cristais passaram por processos de deformação, o que leva a inferir sua proveniência a partir dos gnaisses do "Complexo Kinzigítico” regional, dos granitóides pré a sin-colisionais e dos granulitos costeiros, não ficando excluída a possibilidade da proveniência a partir das coberturas sedimentares terciárias regionais.

Conforme mencionado no início desse artigo, basaltos toléticos amigdaloidais da Formação Cabiúnas são des- critos na base da coluna sedimentar da bacia de Campos, com datação radiométrica entre 134 e 122 Ma. É plausível supor que o intemperismo e a erosão dessas rochas tenham fornecido a associação mineral constituída por ilmenita, magnetita e augita. Chamosita é freqüentemente, encontrada em amígdalas de rochas vulcânicas básicas (Winter, 2001), o que leva a pensar que também é proveniente da referida formação. Além disso, augitas e os referidos opacos podem ter sua origem relacionada aos núcleos gabróicos da suíte G5. Rutilo é, regionalmente, proveniente de terrenos metamórficos de alto grau (Force, 1980) e, em termos locais, provavelmente deriva das rochas granulíticas costeiras.

De acordo com Jordt-Evangelista e Viana (2000), ortoanfibolitos e rochas cálcio-silicáticas entremeados às lentes de mármores do sul do Espírito Santo apresentam, entre sua ampla mineralogia, cristais de grossulária, espinélio e actinolita. Juntamente com outras rochas cálciosilicáticas paraderivadas regionais, essas rochas metamórficas representam as possíveis áreas-fonte destes minerais. A outra granada encontrada nas areias de Iriri, do
Figura 4

Fotomicrografia e espectro EDS de aragonita (6), zircão (7 e 8), cianita (9) e sillimanita (17).

tipo almandina, possivelmente deriva das rochas paragnáissicas do "Complexo Kinzigítico" e granulitos associados e/ou dos granitóides peraluminosos da suíte G2.

Com relação aos polimorfos do Al${ }_{2} \mathrm{SiO}_{5}$, a sillimanita, certamente, provém dos sillimanita-granada-biotita gnaisses paraderivados do "Complexo Kinzigítico" situados próximo à costa do Espírito Santo. Já o terreno Cabo Frio constitui, regionalmente, a área-fonte fornecedora de cianita (Fontanelli et al., 2009). Estando a praia de Iriri a NE de Cabo Frio e considerando que a cianita de Iriri provém de fato desse terreno, a rota de proveniência sedimentar de SW para NE, na bacia de Campos, proposta por esses autores é aqui corroborada.

Entre os minerais pesados das areias negras de Iriri, o zircão é um dos mais abundantes e pode provir de rochas ígneas, metamórficas e sedimentares. Nas areias de Iriri, apresenta-se tanto incolor, euédrico e com inclusões fluidas preservadas quanto marrom, subédrico, com bordas arredondadas e fraturado. $\mathrm{O}$ primeiro subtipo sugere uma população de cristais mais recentes (provavelmente derivados dos litotipos ígneos ácidos 


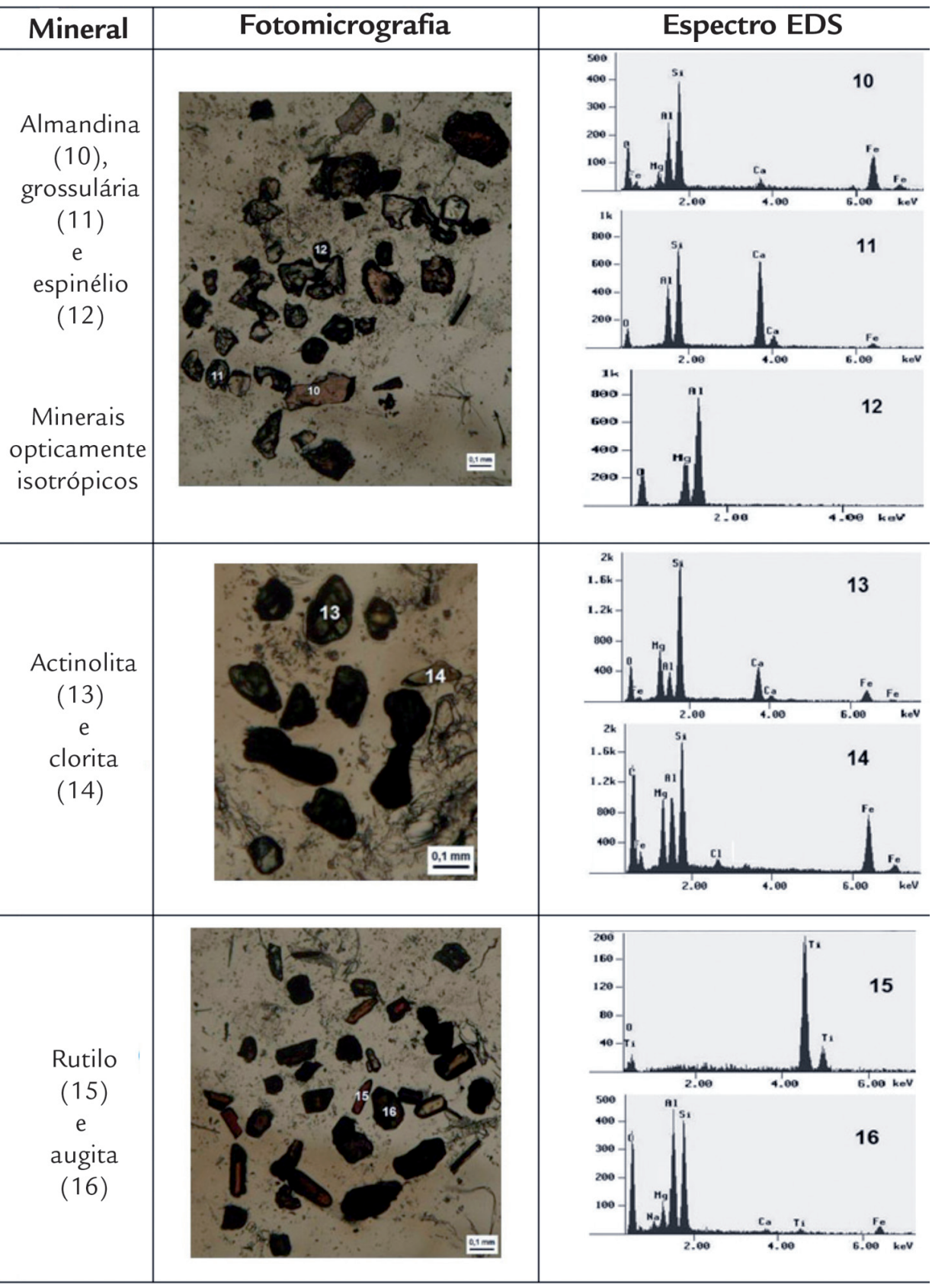

pertencentes às suítes pós-colisonais G4 e G5), enquanto o segundo apresenta características que sugerem outra população de cristais formados há mais tempo e provenientes de rocha-fonte distante da área de deposição (embasamento Paleoproterozóico?), dado o elevado arredondamento das bordas dos cristais marrons. Assim como os zircões incolores, a monazita provém, possivelmente, dos granitóides e pegmatitos das suites póscolisionais G4 e G5.

A aragonita representa uma pequena porção de sedimentos carboná-

\section{Agradecimentos}

Ao laminador Fernando e aos professores A. W. Romano e A. G. ticos do material arenoso estudado e deve possuir uma origem biogênica, estando sua proveniência relacionada aos fragmentos de conchas de moluscos ou corais marinhos (Bessler \& Rodrigues, 2008) trabalhados pelos movimentos das ondas do oceano Atlântico.

Em suma, a areia negra de Iriri é, predominantemente, composta de quartzo ( $45 \%$ em volume) e ilmenita $(35 \%$ em volume). Dada a reduzida metragem cúbica dessas areias negras expostas acima do nível do mar, elas não chegam a constituir um placer de importância eco- nômica em termos de titânio das ilmenitas. Os $20 \%$ restantes compõem-se dos minerais pesados magnetita, monazita, zircão, cianita, sillimanita, almandina, grossulária, espinélio, actinolita, chamosita, rutilo e augita, além de aragonita biogênica. Ressalte-se que a ausência de fragmentos líticos dificultou um melhor aprofundamento da análise de proveniência. A análise feita aqui, entretanto, revela que, tanto a área continental regional, quanto a própria bacia de Campos representam fontes dos sedimentos arenosos estudados.
Costa pelo apoio nas análises micropetrográficas e à estagiária de química
Rafaela pelo apoio na separação com bromofórmio. 


\section{Referências bibliográficas}

BESSLER, K. E., RODRIGUES, L. C. Os polimorfos de carbonato de cálcio - uma síntese fácil de aragonita. Química Nova, v. 31, n. 1, p. 178-180, 2008.

COELHO, F. S., COUCEIRO, P. R. C., LOPES A. L., FABRIS J. D. Óxidos de ferro e monazita de areias de praias do Espírito Santo. Química Nova, v.28, p. 233-237, 2005.

FONTANELLI, P.R., DE ROS, L.F., REMUS, M.V.D. Provenance of Turbiditic Reservoir Sandstones from the Jubarte Oilfield, Campos Basin, Eastern Brazilian Margin. Marine and Petroleum Geology, v.26, p. 1274-1298, 2009.

FORCE E.R. The provenance of rutile. Journal of Sedimentary Petrology. v.50, p. 485-488 1980.

JORDT-EVANGELISTA, H., VIANA, D. J. Mármores da região de Itaoca (ES) e escarnitos no contato com diques máficos e félsicos: mineralogia e petrogênese. Geonomos, v.8, n. 2, p. 61-67, 2000.

KLEIN C., DUTROW B. Manual of mineral science. United States of America: John Wiley and Sons, Inc., 2008. 667p.

MANGE M. A., MAURER H. F. W. Heavy Minerals in Colour. London: Chapman and Hall, 1992. $147 \mathrm{p}$.

MIZUSAKI, A.M.P., THOMAZ FILHO, A., VALENÇA, J.G. Volcano-Sedimentary Sequence of Neocomian age in Campos Basin (Brazil). Revista Brasileira de Geociências, v. 18, p. 247-251, 1988.

REMUS, M. V. D., SOUZA, R. S., CUPERTINO, J. A., DE ROS, L. F., DANI, N., VIGNOL-LELARGE, M. L. Proveniência sedimentar: métodos e técnicas analíticas aplicadas. Revista Brasileira de Geociências, v. 38, n. 2, p. 166-185, 2008. (Suplemento).

SILVA C. G. Pláceres marinhos. Revista Brasileira de Geofísica, v.18, n. 3, p. 327336, 2000.

SUGUIO K. Geologia sedimentar. São Paulo: Editora Edgard Blucher Ltda., 2003. 400 p.

WENTWORTH C. K. A scale of grade and class terms for clastic sediments. Journal of Geology, n. 30, p.377-392, 1922.

WINTER J. D. An introduction to igneous and metamorphic petrology. USA: Prentice Hall, 2001.765p.

Artigo recebido em 19 de janeiro de 2011. Aprovado em 30 de julho de 2011. 